\title{
EFFECTIVENESS OF TEXT MESSAGE REMINDER FOR IMPROVING COMPLIANCE TO TUBERCULOSIS DRUG CONSUMPTION: A SYSTEMATIC REVIEW
}

\author{
Puteri Asma Dewi'), Dumilah Ayuningtyas²) \\ 1)Masters Program in Public Health, Faculty of Public Health, Universitas Indonesia \\ 2)Department of Health Policy and Administration, \\ Faculty of Public Health, Universitas Indonesia
}

\begin{abstract}
Background: Patients with tuberculosis take long-term medication for 6 to 9 months. It causes a risk of drug interruption. A reminder during undergoing treatment is needed to increase obedience and discipline among patients. In Asia, the reminder text messages were in the form of Short Message Service (SMS). It is an alternative reminder for patients to take medication. This study aimed to systematically review the effectiveness of text message reminder for improving compliance to tuberculosis drug consumption.

Subjects and Method: A systematic review were conducted by searching articles from 2 databases, namely PubMed and ProQuest. The keywords were "effectiveness", "tuberculosis", "adherence", and "reminder". The inclusion criteria were Randomized Controlled Trials (RCT) study or quasi experimental study with or without a control group. The articles was selected by PRISMA flow diagram method.

Results: From the 10 articles collected, those reported that text messages reminder influenced patients to take medication. Five articles reported significant increase of patient adherence to take medication using text messages reminder than without text messages reminder $(\mathrm{p}<0.010)$. Effective intervention to improve tuberculosis patient adherence to take medication were based on text messages reminder. The effective TB management was needed in order to increase compliance in tuberculosis treatment.

Conclusion: Text messages reminder can increase tuberculosis patient adherence to take medication.
\end{abstract}

Keywords: adherence, tuberculosis, text messages reminder

\section{Correspondence:}

Puteri Asma Dewi. Masters Program in Public Health, Faculty of Public Health, Universitas Indonesia, Depok, West Java. Email: putri.asma@gmail.com. Mobile: 085606793799.

The $6^{\text {th }}$ International Conference on Public Health

Best Western Premier Hotel, Solo, Indonesia, October 23-24, 2019 | 342

https://doi.org/10.26911/the6thicph.05.07 